\title{
Intraday Patterns in the Trading Volume of the SPY ETF
}

\author{
Emiliano Giudici, PhD. \\ Department of Economics and Finance \\ Stephen F. Austin State University \\ PO Box 13009, SFA Station \\ Nacogdoches \\ Haiying Hu, MPA \\ School of Accounting \\ Stephen F. Austin State University \\ Jiao Tong University, Shanghai \\ China
}

\begin{abstract}
Literature indicates that trading volumes of stocks and ETFs tends to be high at open and at market close. Explanations for this pattern include information based trading (leading to high trading volumes at open) and portfolio rebalancing (leading to high volumes at the end of the day). Using different models, we examine the minute-by-minute trading volumes of the SPY ETF from 2008 to 2014. We find that a) the variation of trading volume through the trading day is U-shaped; b) we identified 12:45 to13:00 as the time of day with the lowest trading activity; c) the patterns of intraday trading volumes vary by weekday and by the overall daily price dynamics. Our findings could help high frequency traders and large investors who are seeking optimal trading times to place large orders while minimizing their impact on ETF prices.
\end{abstract}

Keyword: ETFs, Trading Volume, Market Microstructure, Financial Instruments, Intraday Returns JEL codes: G120, G190, G230

\section{Introduction}

With the increased availability of transaction level data, many studies have examined how volume, returns and risk change through the trading day. At a first glance, many studies show that the trading volume of assets tends to be high at market open, it decreases until about noon and it picks up gradually until market close, resembling the shape of a "U". Knowing the presence of predictable patterns in the trading volumes of securities is important to investors who aim to successfully find a counterpart to a buy or sell order.

The U-shaped pattern of intraday trading volume has been documented across financial instruments, trading venues and time periods. In the U.S. equity markets, Blau (2009) finds U-shaped volumes in NYSE traded stocks, Wang and Wang (2016) find it in the SPDR ETF. Abhyankar (1997) finds U-shaped volumes in the London Stock Exchange, Lee (2001) finds it in the Taiwanese Stock Exchange and Hussain (2011) finds it in the DAX 30. High volumes at open and close are also found in derivatives markets: Peterson (1990) finds them in the CBOE and Eaves (2010) finds this pattern in the Tokyo futures exchange. Furthermore, while the general patterns of intraday volumes are consistent, Kimatz (2003) show that there are differences in volume by day of the week - with peaks on Tuesdays and minimum volumes on Monday and Fridays.

The variation in intraday volumes has been explained in terms of interactions between informed and liquidity traders. Liquidity traders need to trade to meet liquidity needs, which are random in nature, while informed traders will trade only in response to information. To the extent that information clusters during non-trading hours, it could explain the high volume at market open. On the other end, the need to rebalance portfolios (in mutual funds or ETFs) could be responsible for increasing the trading volume around market close.

Studies in intraday volatility patterns have less consensus: Agarwall (2013) and Eaves (2010) find a reversed J-shape intraday volatility in Indian and Japanese futures, respectively. Diao (2015) does not find such pattern in the CSI300. Finally, studies on intraday returns do not illustrate a clear pattern, indicating that intraday returns have dynamics that are even more complex than volume or volatility.

Overall, while the literature on intraday trading volumes seems to focus on the general shape of the intraday trading volumes, we did not find any study that identifies the time when the trading volume is at its lowest. 
Knowledge and predictability of the intraday trading volumes could be beneficial to a) day traders, who may not be able to execute a strategy in a timely fashion due to market illiquidity; b) institutional investors who need to rely on an algorithm to break a large order into smaller ones to minimize the price impact of their trade; and c) to informed investors who want to conceal their trades to avoid revealing their strategy.

This paper contributes to the literature in a number of ways. First, we estimate the time of the day in which trading volume is lowest and the potential for a significant price impact of a large trade is highest. Second, we examine the impact of a number of factors on the time of lowest volume (namely day of the week, daily market trend and daily volatility). Last, to our knowledge, this study is unique as it examines the issue using a large dataset consisting of minute level transactions over a period of nearly a decade.

\section{Data and Methodology}

\section{2a. Data}

We collected prices and volumes for every trading minute of the SPDR S\&P500 ETF (SPY) from Tick Data for a period spanning January 2, 2008 to December 31, 2014, totaling 686,480 trading minutes. This time interval covers both a bull and a bear market. Using the prices from open to open we computed the returns, and we computed the volatility as the spread between high and low as a percentage of the mid-point. Furthermore, we divided the volume in each minute by the total volume of that day. This allowed us to express what percentage of daily trading volume is traded in a given minute.

Following the literature ${ }^{1}$, the trading volumes in each minute were divided into 15 minutes buckets, starting at open, with the first bucket spanning 9:30 until 9:45, the second starting at 9:45 and ending at 10:00 and so forth. The volumes in each bucket were then combined across the entire sample. Each bucket contains about 26,445 observations $^{2}$. The mean, median and the $90^{\text {th }}$ and $10^{\text {th }}$ percentiles were computed. The results are plotted in Figures $1 \mathrm{a}$ and $1 \mathrm{~b}$.

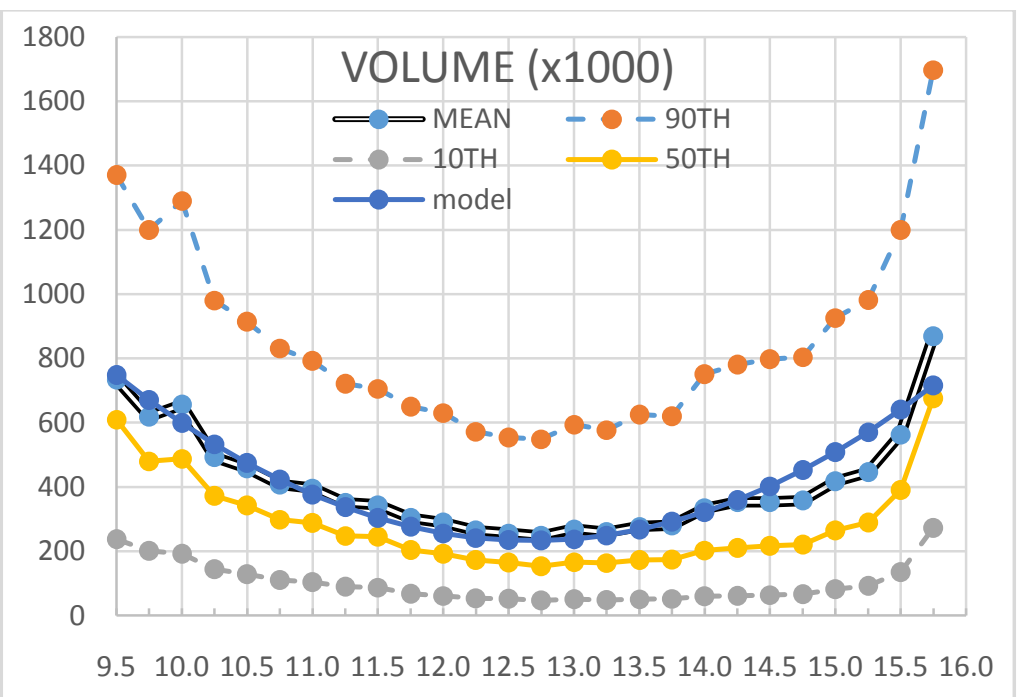

Figure 1a. Trading volume versus trading hour, grouped in 15-minute buckets. The abscissa shows the time in which the bucket begins. The line overlapping the mean show the predicted values of the quadratic model. Each value is obtained by averaging the volume in the corresponding bucket for each day in the sample.

Figures $1 \mathrm{a}$ and $1 \mathrm{~b}$ show that volume starts strong at open and tends to decline through the day. It appears to reach a minimum between 12:15 and 13:00 and then it begins to pick up steadily through the rest of the trading day, reaching a peak in the last trading minutes. This trend is visible not only in the mean but also in the median and the extreme percentiles. The same trend is visible when volume is expressed as a percentage of the daily trading activity (Figure 1b). The findings in our sample are consistent with the literature on intraday trading volume.

\footnotetext{
${ }^{1}$ See Peterson (1990), Blau (2009), McInish and Wood (1992).

215 minutes times 1763 days. 


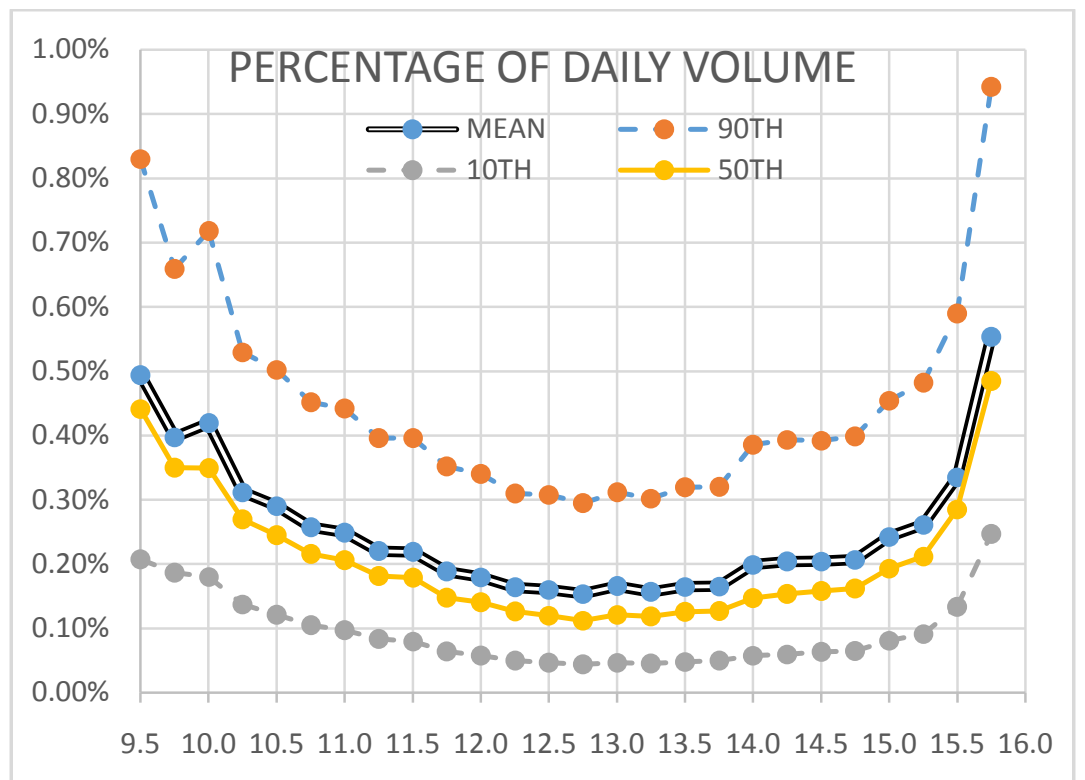

Figure $1 \mathrm{~b}$. Percentage of daily trading volume versus trading hour, grouped in 15 -minute buckets. The abscissa shows the time in which the bucket begins. Each value is obtained by averaging the percentage of daily volume in the corresponding bucket for each day in the sample.

The literature shows that trading volumes vary by weekday. For instance, Kimatz (2003) find that in several countries trading volumes are highest on Tuesday and lowest on Monday and Friday. To check this possibility, we subdivided the sample of volumes and percentages of daily volume by day of the week. The means of each of the 15-minute buckets are plotted in Figures $2 \mathrm{a}$ and $2 \mathrm{~b}$. Both figures show that the U-shaped pattern is typical of every day of the week. Every day the lowest trading volume occurs between 12:30 and 13:00. Furthermore, Figure 2a seems to indicate that for every time interval, Monday's volume is the lowest. Wednesdays display the highest trading volumes of the week only for the time between 13:45 and 15:00. Fridays, on the other hand, tend to start and end with strong volumes. If the volume thorough the day is scaled by the total volume, many of the differences across weekdays tend to disappear (see Figure 2b). The only difference is the concentration of trading volume occurring on Wednesdays between about 13:45 and 15:15.

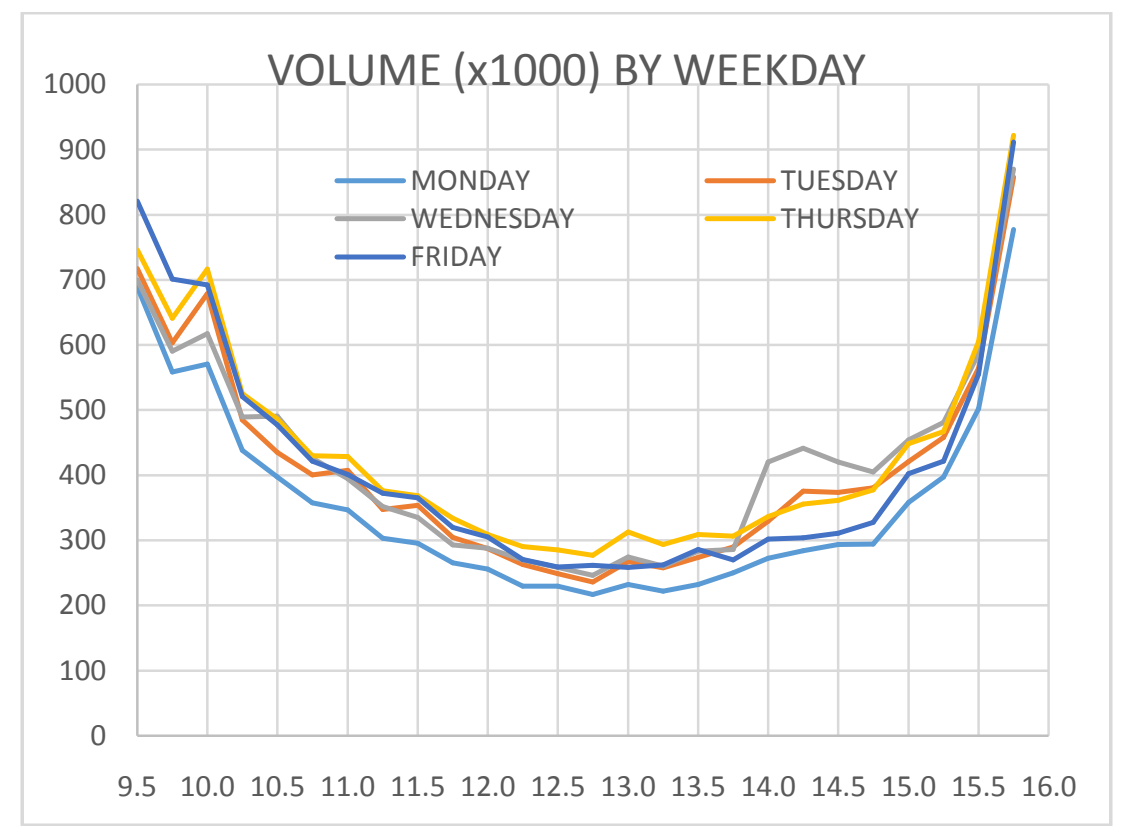

Figure 2a. Trading volume versus trading hour, grouped in 15-minute buckets subdivided by day of the week. At every hour, Friday's volume is the lowest. 


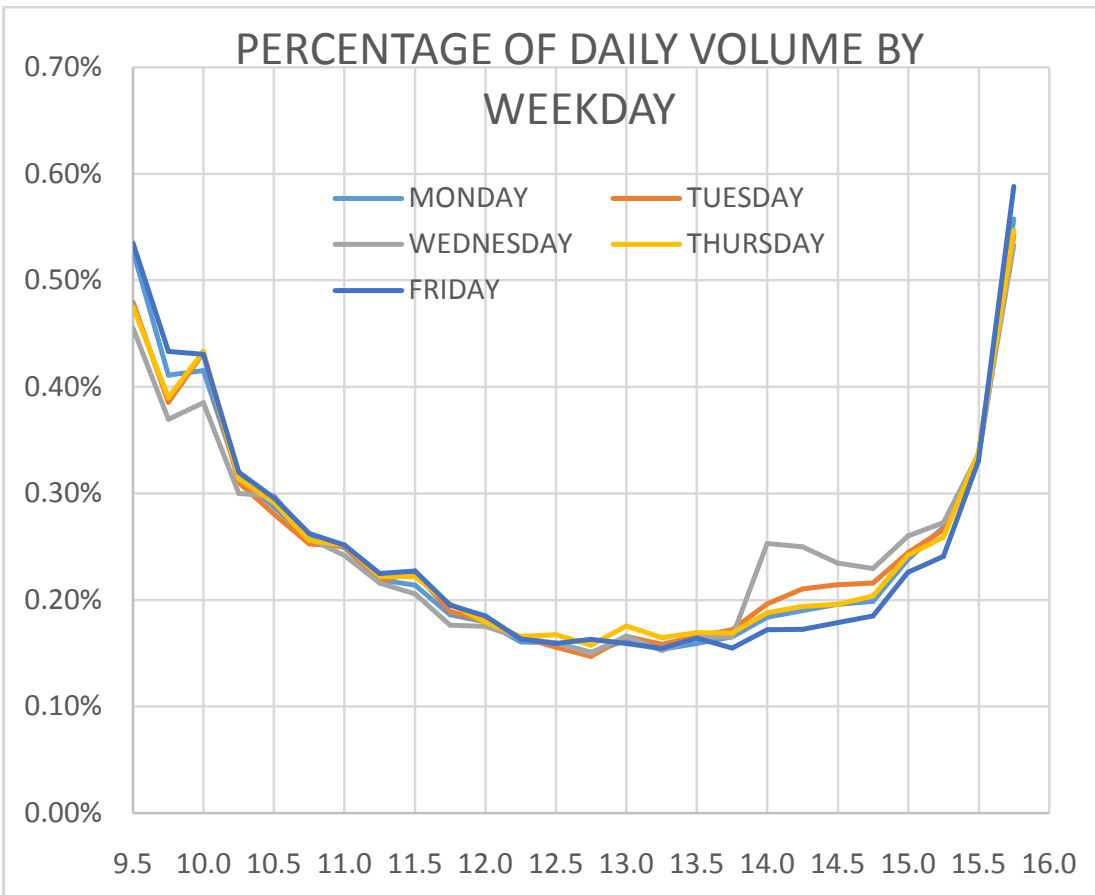

Figure $2 \mathrm{~b}$. Percentage of daily trading volume versus trading hour, grouped in 15-minute buckets subdivided by day of the week.

Although not central to the scope of this paper, we examined the returns and the volatility. The descriptive statistics are plotted in Figures 3a, 3b, 4a and 4b. Figure 3a shows that the average return in each bucket does not follow a remarkable pattern through the trading day, except for increasing magnitudes in the last trading hour and a half. However, the $90^{\text {th }}$ and $10^{\text {th }}$ percentile of returns follow opposite patterns: the highest returns are more extreme in the early trading hours, they reach a minimum around 12:45 and gradually increase as market close approaches. A similar trend occurs with the $10^{\text {th }}$ percentile of returns. They are more extreme at open, reach a minimum around 12:45 and become more extreme in the second half of the trading day.

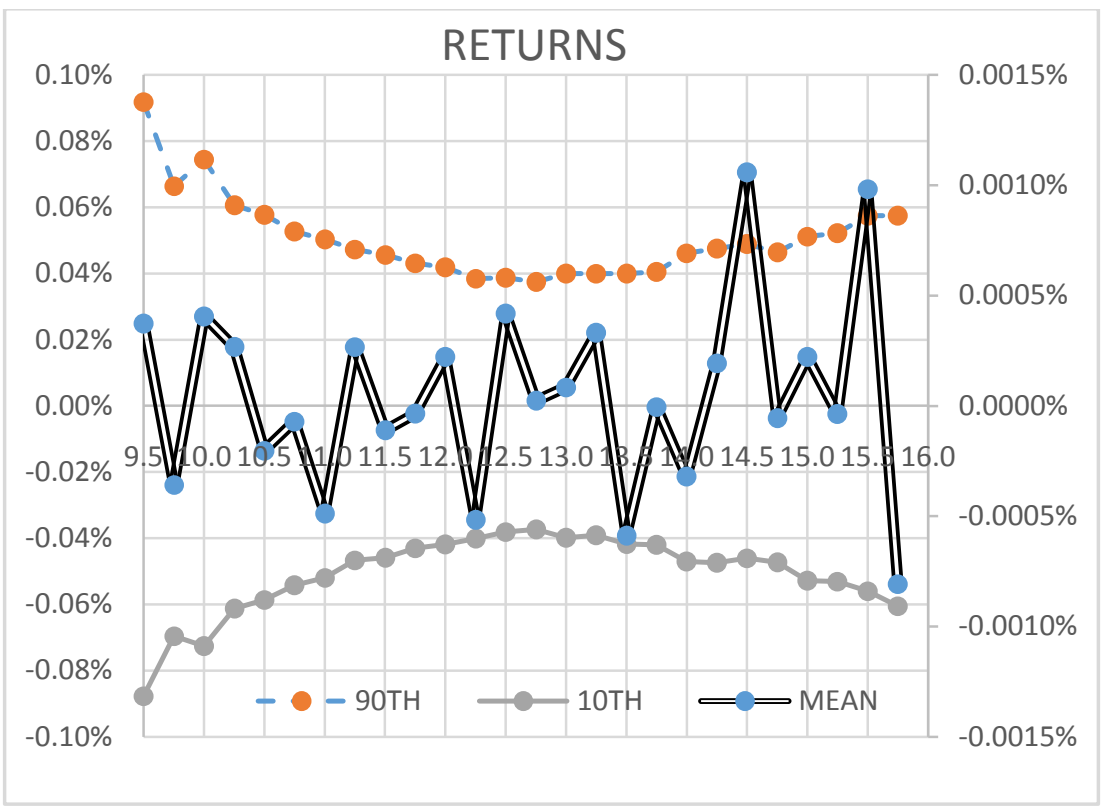

Figure 3a. Returns in each 15-minute bucket. The mean return is plotted in the secondary axis. Note the U and reversed-U shape pattern for extreme returns.

Figure $3 \mathrm{~b}$ reports the average of the returns of each of the 15 minute buckets and subdivides them by day of the week. On average, Fridays at open and Wednesdays at close appear to experience the lowest returns. 
Tuesday experiences the highest returns in the first trading hour, but also the most extreme in the first two. Overall, the returns through the trading day don't seem to follow a pattern as remarkable as volume.

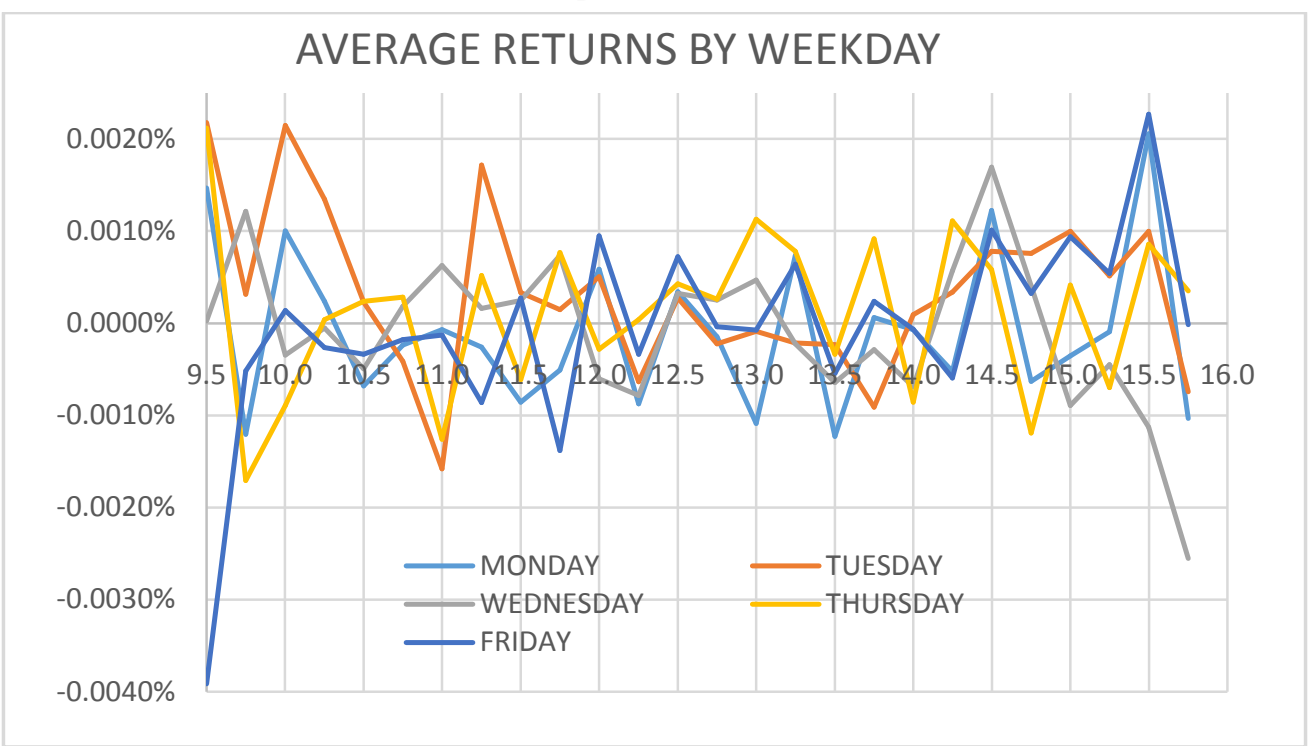

Figure 3b. Returns in each 15-minute bucket subdivided by day of the week. Friday seems to experience the lowest average return at open, while Wednesdays experience the lowest return at close.

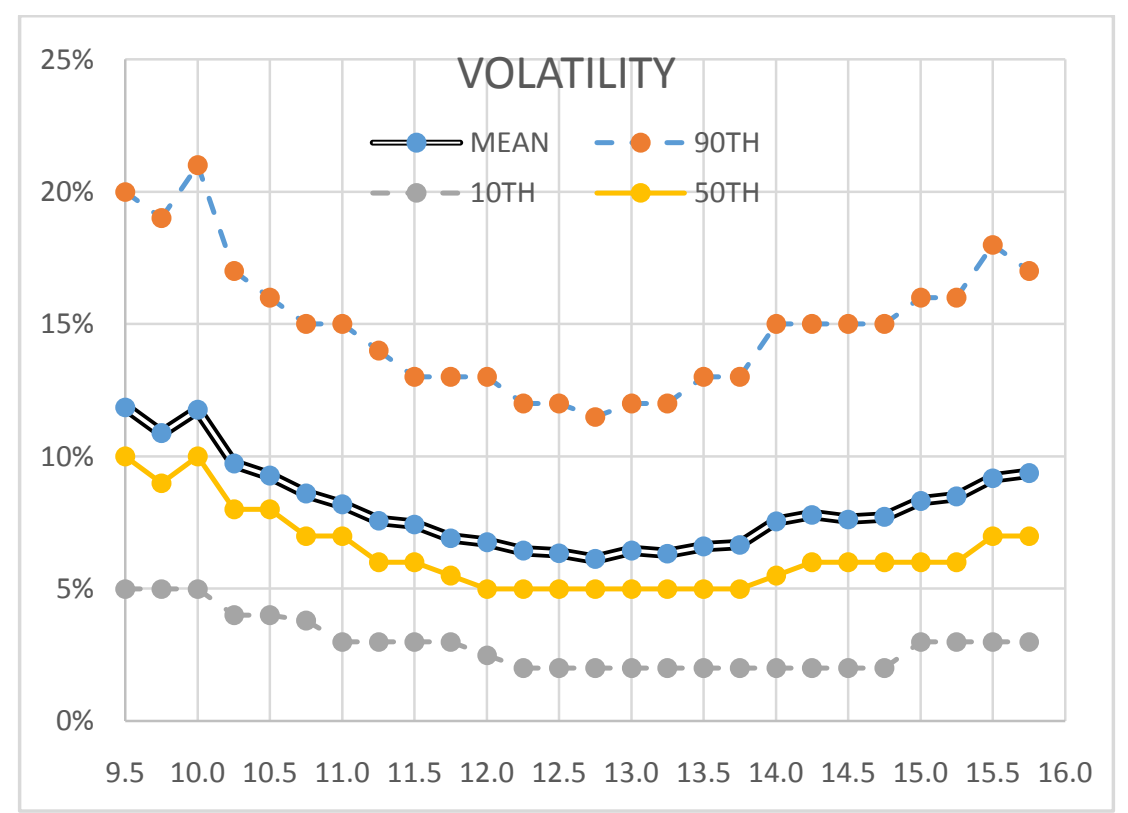

Figure $4 \mathrm{a}$. Average, median $10^{\text {th }}$ and $90^{\text {th }}$ percentile of volatility for each 15 -minute bucket in the trading day. . Note the $\mathrm{U}$ shape of volatility, which tends to peak at open and close, but reaches a minimum between 12:30 and 13:00.

Figure 4a shows that the volatility tends to be higher at open and close, while tends to be lower around 12:45. This pattern is very similar to that of volume, except volume tends to peak at the end of the day while volatility peaks at market open. Figure $4 \mathrm{~b}$ compares the intraday volatilities by day of the week. Friday has the highest volatility of the week in the first half of the trading day, while Mondays have the lowest volatility at most of the trading times. Similarly to the volume, volatility peaks on Wednesdays from 13:45 to about 15:30. 


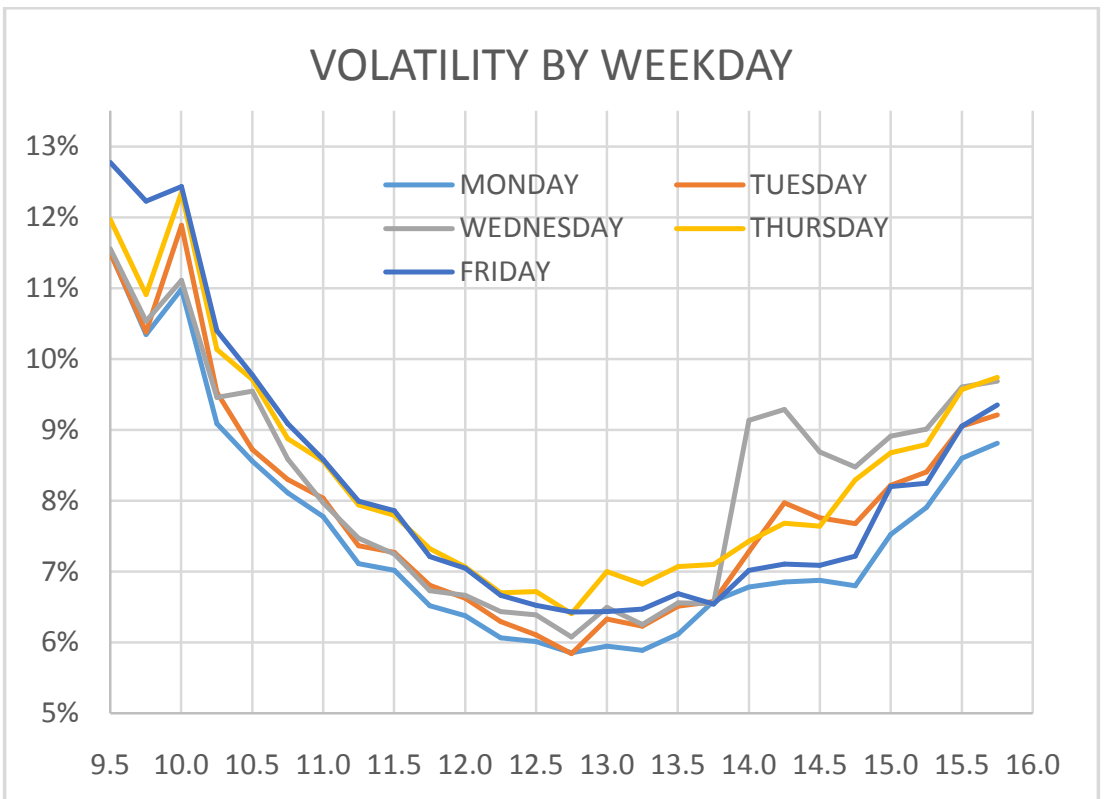

Figure 4b. Volatility in each 15-minute bucket subdivided by day of the week. Fridays exhibit the highest volatility at open and in the first half of the trading day. Monday experiences the lowest volatility most of the day

To further investigate how our data differs by day of the week, we regressed each variable on dummies representing each day of the week. The day with lowest parameter was taken as the reference point. The results are reported in Table 1. The regressions at the aggregate level confirm the graphs: volume and volatility are lowest on Mondays, we do not find differences in the returns by day of the week.

Table 1: Volatility, Volume and Returns by day of the week

\begin{tabular}{|c|c|c|c|c|c|c|c|c|}
\hline & \multicolumn{2}{|c|}{ VOLATILITY } & \multicolumn{2}{|l|}{ RETURNS } & \multicolumn{4}{|c|}{ VOLUME } \\
\hline Variable & Coeff & t-Stat & Coeff & t-Stat & Coeff & t-Stat & $\begin{array}{l}95 \% \mathrm{CI} \\
\text { Low }\end{array}$ & High \\
\hline $\mathrm{C}$ & 0.07551 & $395^{*}$ & $-6.75 E-07$ & -0.34 & 362061 & $280 *$ & & \\
\hline Mon & & & & & & & 359525 & 364595 \\
\hline Tue & 0.003795 & $14.3 *$ & 4.01E-06 & 1.48 & 52089 & $29 *$ & 411720 & 416578 \\
\hline Wed & 0.007089 & $26.8 *$ & $-1.80 \mathrm{E}-07$ & -0.07 & 64111 & $36^{*}$ & 423744 & 428599 \\
\hline Thu & 0.008621 & $32.4 *$ & $1.81 \mathrm{E}-06$ & 0.66 & 78928 & $44 *$ & 438530 & 443447 \\
\hline Fri & 0.007179 & $26.9 *$ & 7.87E-08 & 0.03 & 60534 & $34 *$ & 420123 & 425065 \\
\hline Adjusted R-squared & 0.001971 & & $-1 \mathrm{E}-06$ & & 0.00321 & & & \\
\hline
\end{tabular}

Note: Sample size 686,$480 ; *$ denotes significance at the $1 \%$ level

To detect the differences in volume, volatility and returns by the time in the trading day, we regressed the variable of interest on dummies representing each time bin. We omitted the time slot 12:45 because it appeared to be the one with the lowest trading volume and volatility. The results of the regressions are reported in Table 2. Volume at all time bins is significantly greater than that of the $12: 45 \mathrm{bin}$. The representation of volume as a percentage of the daily activity generally agrees with the raw volumes, but the interval at 13:25 is not statistically different than the 12:45 bin. Volatility is also greater than that of the $12: 45$ bin at all times, hence confirming the U-shaped intraday pattern in the plots. 
Table 2: Volume, Percentage of Daily Volume and Volatility Relative to 12:45 Bucket

\begin{tabular}{|c|c|c|c|c|c|c|}
\hline & \multicolumn{2}{|c|}{ VOLUME } & \multicolumn{2}{|c|}{ \% DAILY VOLUME } & \multicolumn{2}{|c|}{ VOLATILITY } \\
\hline & Coeff & t-Stat & Coeff & t-Stat & Coeff & t-Stat \\
\hline $\mathrm{C}$ & 247638 & 93.1 & 0.00154 & 118.1 & 0.06124 & 148.8 \\
\hline TIME 950 & 487176 & 129.5 & 0.00340 & 184.8 & 0.05738 & 98.6 \\
\hline TIME 975 & 371642 & 98.8 & 0.00244 & 132.4 & 0.04756 & 81.7 \\
\hline TIME_1000 & 408479 & 108.6 & 0.00266 & 144.3 & 0.05636 & 96.9 \\
\hline TIME_1025 & 244821 & 65.1 & 0.00158 & 85.9 & 0.03604 & 61.9 \\
\hline TIME_1050 & 210472 & 56.0 & 0.00137 & 74.3 & 0.03147 & 54.1 \\
\hline TIME_1075 & 160155 & 42.6 & 0.00104 & 56.3 & 0.02473 & 42.5 \\
\hline TIME_1100 & 148689 & 39.5 & 0.00095 & 51.7 & 0.02064 & 35.5 \\
\hline TIME_1125 & 102901 & 27.4 & 0.00066 & 36.0 & 0.01458 & 25.1 \\
\hline TIME_1150 & 96636 & 25.7 & 0.00065 & 35.4 & 0.01317 & 22.6 \\
\hline TIME_1175 & 56084 & 14.9 & 0.00035 & 18.9 & 0.00798 & 13.7 \\
\hline TIME_1200 & 41784 & 11.1 & 0.00026 & 14.1 & 0.00636 & 10.9 \\
\hline TIME_1225 & 17244 & 4.6 & 0.00010 & 5.5 & 0.00312 & 5.4 \\
\hline TIME_1250 & 8777 & 2.3 & 0.00007 & 3.6 & 0.00231 & 4.0 \\
\hline TIME_1300 & 21675 & 5.8 & 0.00012 & 6.5 & 0.00323 & 5.5 \\
\hline TIME_1325 & 11841 & 3.1 & $0.00003^{\mathrm{a}}$ & 1.6 & 0.00214 & 3.7 \\
\hline TIME_1350 & 29623 & 7.9 & 0.00011 & 5.9 & 0.00472 & 8.1 \\
\hline TIME_1375 & 33084 & 8.8 & 0.00012 & 6.3 & 0.00548 & 9.4 \\
\hline TIME_1400 & 85728 & 22.7 & 0.00046 & 24.7 & 0.01424 & 24.4 \\
\hline TIME_1425 & 105966 & 28.1 & 0.00050 & 27.2 & 0.01677 & 28.8 \\
\hline TIME_1450 & 105588 & 28.0 & 0.00051 & 27.4 & 0.01504 & 25.8 \\
\hline TIME_1475 & 110536 & 29.3 & 0.00053 & 28.8 & 0.01587 & 27.2 \\
\hline TIME_1500 & 170081 & 45.1 & 0.00089 & 48.1 & 0.02195 & 37.6 \\
\hline TIME_1525 & 198332 & 52.6 & 0.00108 & 58.4 & 0.02359 & 40.5 \\
\hline TIME_1550 & 315886 & 83.8 & 0.00182 & 98.4 & 0.03062 & 52.5 \\
\hline TIME_1575 & 740201 & 199.5 & 0.00489 & 269.1 & 0.03467 & 60.4 \\
\hline Adjusted & 0.14022 & & 0.235433 & & 0.055 & \\
\hline
\end{tabular}

NOTES: $a$ denotes a variable not significant at the $10 \%$ level. All other variables are significant at the $1 \%$ level. All values are relative to the time bin 12:45. Variables are coded by the time in which the bucket begins in 15 minute intervals: e.g. TIME_1325 is a bucket starting at 13:15, TIME_1350 corresponds to a bucket starting at 13:30 and so forth.

\section{2b. Methodology}

Examining the coefficients in Table 2 for both the volume and the volume as a percentage of daily activity, suggests that they become progressively larger at increasing rates for times earlier than 12:45 and for times later than 13:00. However, using the 15-minute bins does not allow to precisely measure the time at which volume is smallest, as the bins are constructed with arbitrary size and starting times. To avoid this issue we propose modeling the daily trading volume as a quadratic in time:

$$
V O L U M E_{t}=\alpha T I M E_{t}^{2}+\beta T I M E_{t}+\gamma+\varepsilon_{t}
$$

Where VOLUME is the trading volume at a specific minute, TIME is the time at which the trading volume is taking place. This variable ranges between 9.5 to 16.0 in increments of 1/60. This model allows us to capture the u-shaped trend in the day and it allows to compute the location of its minimum:

$$
t_{V \min }=-\frac{\beta}{2 \alpha}
$$

The results of the regression (1) computed over the entire sample is reported in Table 2, and the predicted values are reported in Figure 1a.

While Equations 1 and 2 can be used to estimate a value at which the time of minimum volume occurs, it does not provide information about its distribution. To circumvent this issue, we divide the sample by trading days, fit the model (1) every day and collected the coefficients and other relevant statistics. We then calculated the value of the minimum trading volume for every day using (2). This produced a sample of $t_{V \min }$ consisting of 1747 observations. 
This approach generates a distribution of $t_{V \min }$, and it allows us to investigate the possible factors that impact its variability. Specifically, we test for differences by weekday (Equation 3) and by the daily dynamics of returns (i.e. overall daily return and daily volatility, Equation 4). Equations (3) and (4) are then used to determine if there are systematic factors with the quality of the model. This is accomplished by replacing $t_{V \min }$ with the Adjusted $\mathrm{R}^{2}$ of the daily models.

$$
\begin{gathered}
t_{\text {Vmin }, t}=\alpha+\sum_{\substack{k=\text { Monday } \\
t_{\text {Vmin }, t}=\alpha+\beta \text { RETURN }_{t}+\gamma \text { VOLATILITY } \\
t}}^{\text {Thursday }} \delta_{t} \varepsilon_{t}
\end{gathered}
$$

\section{Results}

The estimates of Equation 1 over the entire sample are reported in Table 3 (e). Applying Equation 2 to the coefficients obtained over the entire sample yields 12.80. This indicates that on average the time with the lowest trading volume is 12:48. The repeated sampling approach described in the previous section allows us to construct a confidence interval around this estimate and it allows us to explore possible explanations for its variability.

\begin{tabular}{|c|c|c|c|c|c|c|c|c|c|c|}
\hline & \multicolumn{2}{|c|}{ (a) $\boldsymbol{t}_{V \min }$} & \multicolumn{2}{|c|}{ (b) $t_{V \min }$} & \multicolumn{2}{|c|}{ (c) Adj. $R^{2}$} & \multicolumn{2}{|c|}{ (d) Adj. $R^{2}$} & \multicolumn{2}{|c|}{ (e) VOLUME } \\
\hline Variable & Coeff & $\begin{array}{l}\text { t-Stat } \\
585\end{array}$ & $\begin{array}{l}\text { Coeff } \\
5777\end{array}$ & t-Stat & Coeff & t-Stat & Coeff & t-Stat & $\begin{array}{l}\text { Coeff } \\
8604954\end{array}$ & t-Stat \\
\hline MONDAY & -0.0554 & $-1.75 *$ & & & & & 0.18216 & 25.3 & & \\
\hline TUESDAY & -0.0983 & -3.18 & & & & & 0.16268 & 23.4 & & \\
\hline WEDNESDAY & -0.1713 & -5.53 & & & & & 0.15417 & 22.1 & & \\
\hline THURSDAY & -0.0530 & $-1.70 *$ & & & & & 0.15918 & 22.6 & & \\
\hline RETURNS & & & 11214 & 3.5 & 360.04 & 4.7 & & & & \\
\hline VOLATILITY & & & 7890 & 36.0 & 184.44 & 35.5 & & & & \\
\hline $\begin{array}{l}\text { HOUR } \\
\text { HOUR }^{2}\end{array}$ & & & & & & & & & $\begin{array}{l}-1307976 \\
5108705\end{array}$ & -306.9 \\
\hline Adj. $R^{2}$ & 0.017 & & 0.337 & & 0.331 & & 0.336 & & 0.121 & \\
\hline obs & 1747 & & 2556 & & 2556 & & 2556 & & 686480 & \\
\hline
\end{tabular}

Table 3: Time of minimum volume, fit and raw volume fit by hour, day, returns and volatility

NOTES: All variables are significant at the $1 \%$ level, except those denoted by *, which are significant at the $10 \%$ level.

Table 3(a) examines how the slowest trading time varies through the week. The model estimates that on Friday the lowest trading volume occurs at 12:56, while the other days the lowest volume occurs earlier. In particular, Wednesdays experience the slowest trading at 12:46.

The dynamics of trading appears to impact the time of slowest volume as well. Table 2(b) suggests that high returns and high volatility tend to delay the time of day when minimum trading takes place.

Knowledge of the timing of the slowest trading time of the day could be meaningful in several scenarios. For instance, should a trader need to place a large order in a thin market its execution could have a considerable price impact, hence increasing the transaction cost. In this scenario, algorithmic trading could break the order in subsets to minimize the price impact. However, ability to predict the behavior of volume would allow the algorithm to break and time the order to minimize impact and increase time of execution.

Lastly, we explored whether the quality of the model changes systematically in response to observable factors. Columns (c) and (d) explore the quality of the regressions used to estimate the daily $t_{V \min }$ by day of the week and the daily return dynamics. The average coefficient of determination on Fridays tends to be lower than any of the other weekdays, with Mondays being the better fitted days. Similarly, days with high returns and high volatility tend to be better candidates for the model in equation 1.

Overall, this study confirms the findings intraday volume and volatility tend to have a U-shape: they start high, decrease through the day, reach a minimum around noon and then they progressively increase. A closer look to the volume data shows that the minimum volume occurs at 12:56 on a Friday and at earlier times the rest of the week, with Wednesday at 12:46 being the earliest. The time in which trading volume is the thinnest depends on the overall volatility and the returns dynamics: days with higher volatility and bullish returns tend to experience the lowest trading volume later in the day. 


\section{Conclusions}

In this paper we examined the intraday trading volume of the SPY ETF over the period 2008 through 2014 at the minute level. We find that the both trading volume and volatility vary through the day by starting high, decreasing rapidly, reaching a minimum around noon and then progressively increasing. While the literature is rich with illustrations of this general behavior, we contribute to it in two ways: first we use a dataset that is both longer and sampled at a higher frequency than other studies. Second, we estimate the time at which trading is at its slowest (and potential for price impact is at its highest). We find that time at which the slowest volume occurs varies by weekday and is affected by the general dynamics within the trading day. These results could be useful to both day traders and large traders in a number several ways. First, these findings can serve as a basis to predict the price impact of trades; second, to develop strategies for segmenting large trades and last, to develop strategies of order timing.

\section{References}

Abhyankar, A., Ghosh, D., Levin, E., \&Limmack, R. J. 1997. Bid-Ask Spreads Trading Volume and Volatility: IntraDay Evidence From the London Stock Exchange, Journal of Business Finance \& Accounting, 24(3) \& (4), 0306-686X.

Agarwalla, S. K. 2013. Expiration-Day Effects and The Impact Of Short Trading Breaks On Intraday Volatility: Evidence From the Indian Market, The Journal Of Futures Markets, Vol. 33, No. 11, 1046-1070.

Admati, Anat., \&Pfleiderer, P. 1988. A Theory Of Intraday Patterns: Volume and Price Variability, The Review Of Financial Studies, Vol. 1, No.1, 3-40.

Admati, Anat., \&Pfleiderer, P. 1989. Divide And Conquer: A Theory Of Intraday and Day-Of- The -Week Mean Effects, The Review Of Financial Studies, Vol.2, No. 2, 189-223.

Abraham. A.,\&Ikenberry D.L. 1994. The Individual Investor and the Weekend Effect, The Journal Of Financial And Quantitative Analysis, Vol. 29, No.2, 263-277.

Blau, B. M., Ness, B. F. V., \& Ness, R. A. V. 2009. Intraday Stealth Trading : Which Trades Move Prices During Periods of High Volume?, The Journal Of Financial Research, Vol. xxx ii, No.1, 1-21.

Broussard, J.P., \&Nikiforov, A. 2014. Intraday Periodicity in Algorithmic Trading, Journal Of International Financial Markets, Institutions \& Money, 30, 196-204.

Diao, X., Tong, B.2015.Forecasting Intraday Volatility andVaR Using Multiplicative Component Garch Model, Applied Economics Letters, Vol. 22, No.18, 1457-1464.

Eaves, J., \& Williams, J. 2010. Are Intraday Volume and Volatility U-Shaped After Accounting for Public Information?American Journal ofAgricultural Economics, 92(1):212-227.

Foster, F., \&Viswanathan, S. 1990. A Theory Of The Intraday Variations in Volume, Variance, and Trading Costs In Securities Markets, The Review of Financial Studies, Vol. 3, No. 4(1990), pp. 593-624.

Fuertes, A., Kalotychou, E., \&Todorovic, N. 2015. Daily Volume, Intraday and Overnight Returns for Volatility Prediction: Profitability or Accuracy?,Review of Quantitative Finance and Accounting.45:251-278.

Goodhart, C. A. E., \& O’ Hara, M. 1997. High Frequency Data in Financial Markets: Issues and Applications, Journal Of Empirical Finance, Vol. 4, 73-114.

Hendershott, T., \& Riordan R. 2018. Algorithmic Trading and the Market For Liquidity, The Journal Of Financial And Quantitative Analysis, Vol. 48, No.4.

Hendershott, T., Jones C. M., \&Menkveld A. J. 2011. Does Algorithmic Trading Improve Liquidity?,The Journal Of Finance, Vol. 66, No. 1, 1-33.

Heston, S. L., Korajczyk, R. A., \&Sadka, R. 2010. Intraday Patterns in the Cross-Section of Stock Returns, The Journal Of Finance, Vol. 65, No. 4, 1369-1407.

Hussain, S. M. 2011. The Intraday Behavior of Bid-Ask Spreads, Trading Volume and Return Volatility: Evidence From Dax 30, International Journal Of Economics And Finance, Vol. 3, No. 1.

Jain, P. C. \& Joh, G. H. 1988. The Dependence Between Hourly Prices And Trading Volume, The Journal Of Financial And Quantitative Analysis, Vol. 23, No. 3, 269-283.

Juergens, J. L., \& Lindsey, L. 2009. Getting Out Early: An Analysis of Market Making Activity at the Recommending Analyst's Firm, The Journal Of Finance, Vol. 64, No.5, 2327-2359.

Kirilenko, A. A., \& Lo, A. W. 2013. Moore's Law Versus Murphy's Law: Algorithmic Trading and its Discontents, The Journal Of Economic Perspectives, Vol. 27, No.2., 51-72.

Karpoff, J. 1987. The Relation Between Price Changes and Trading Volume: A Survey, The Journal Of Financial And Quantitative Analysis, Vol. 22, No.1, 109-126.

O'hara, M., Yao, C., \& Ye, Mao. 2014. What's Not There: Odd Lots and Market Data, The Journal Of Finance, Vol.69, No.5, 2199-2236. 
Peterson, D. 1990. A Transaction Data Study of Day-Of -The-Week and Intraday Patterns in Option Returns, The Journal Of Financial Research, Vol. XIII, No.2.

Rahman, S., Lee, C., \&Ang, K. P. 2002. Intraday Return Volatility: Evidence from Nasdaq Stocks, Review Of Quantitative Finance And Accounting, 19: 155-180.

Shum, P., Hejazi, W., Haryanto, E., \&Rodier, A. 2015. Intraday Share Price Volatility and Leveraged ETF Rebalancing, Review of Finance, 2016, 2379-2409.

Stoll, H. R., \& Whaley, R. 1990. Program Trading and Individual Stock Returns: Ingredients of the Triple-Witching Brew, The Journal Of Business, Vol. 63, No. 1, part 2, 165-192.

Thaler, R. 1987. Anomalies Seasonal Movement in Security Prices II: Weekend, Holiday, Turn Of The Month, And Intraday Effects, The Journal Of Economic Perspectives, Vol.1, No. 2, 169-177.

Lee, Y. T., Fok, R.C., Liu, Y. J. 2001. Explaining Intraday Pattern of Trading Volume from the Order Flow Data, Journal Of Business Finance \& Accounting, 28(1) \& (2).

Lettau, M. \&Madhavan, A. 2018. Exchanged-Traded Funds 101 for Economists, The Journal Of Economic Perspectives, Vol. 32, No.1, 135-154.

Mclnish, T. H. \& Wood, R. A. 1992. An Analysis of Intraday Patterns in Bid/Ask Spreads for Nyse Stocks, The Journal Of Finance, Vol. 47, No.2, 753-764.

Wang, Y., \& Wang, Y. 2016. The Information Content of Intraday Implied Volatility for Volatility Forecasting, Journal Of Forecasting, 35, 167-178.

Zhu, H. 2014. Do Dark Pools Harm Price Discovery?,The Review Of Financial Studies, Vol. 27, No. 3, 747-789. 